\title{
ENERGY-SAVING BUILDING PROGRAM EVALUATION WITH AN INTEGRATED METHOD UNDER LINGUISTIC ENVIRONMENT
}

\author{
Min HUANG ${ }^{1}$, Xinli ZHANG ${ }^{1}$, Ruxue REN ${ }^{1}$, Huchang LIAO ${ }^{1 *}$, \\ Edmundas Kazimieras ZAVADSKAS ${ }^{2}$, Jurgita ANTUCHEVIČIENĖ®3 \\ ${ }^{1}$ Business School, Sichuan University, 610064 Chengdu, China \\ ${ }_{2}^{2}$ Institute of Sustainable Construction, Vilnius Gediminas Technical University, Vilnius, Lithuania \\ ${ }^{3}$ Department of Construction Management and Real Estate, Vilnius Gediminas Technical University, \\ Vilnius, Lithuania
}

Received 29 August 2019; accepted 6 November 2019

\begin{abstract}
In the context of sustainable development, building energy conservation has become the development trend of the construction industry. The selection of energy-saving building program, as a multi-criteria decision-making (MCDM) problem, has a direct influence on the actual energy-saving effect. In this paper, an integrated MCDM method combining the extended best worst method (BWM) and Weighted Aggregated Sum Product Assessment (WASPAS) method is proposed to solve the energy-saving building program selection problem under the linguistic Pythagorean fuzzy environment. The Linguistic Pythagorean fuzzy sets (LPFSs) are used to model the uncertain evaluation information of experts. The extended BWM is developed to determine the weights of criteria, while the extended WASPAS method is proposed to determine the ranking of alternatives. To validate the applicability and reliability of the proposed method, this paper presents a numerical example of the selection problem for energy-saving building programs. Some managerial insights are also given for practitioners to use the proposed method.
\end{abstract}

Keywords: energy-saving building, construction industry, multi-criteria decision making, linguistic Pythagorean fuzzy set, weighted aggregated sum product assessment, best worst method.

\section{Introduction}

The United Nations convened the Conference on Environment and Development with sustainable development as its core content in 1992. Since then, the concept of sustainable development has been widely recognized (Heravi et al., 2017). All countries in the world have realized the importance of sustainable development and made efforts to put it into practice. Sustainable development refers to the coordinated development of economy, society, resources and environmental protection, in which saving resources and energy and protecting natural ecological environment are important contents. Nowadays, the global economy and society are developing fast, and the demand of energy is increasing constantly. Energy production and application and the impact on the environment have become major concerns of the public (Chenari et al., 2016). The construction industry is one of the major energy consumers. According to the statistics, construction accounts for $40 \%$ of global energy consumption and the resulting greenhouse gases are responsible for $30 \%$ of global energy-related emissions. Besides, the construction industry consumes more than $10 \%$ of water resource and generates more than $30 \%$ of waste, which leads to great harm to the environment (Si \& Marjanovic-Halburd, 2018). The implementation of energy-saving building is considered to be the most successful carbon dioxide emission reduction and energy-saving strategy (Huang \& Wang, 2014). Energy-saving buildings refer to buildings that use energy reasonably and improve energy efficiency without affecting living comfort. Therefore, to realize the sustainable development of the construction industry, it is critical to adopt building energy-saving measures to increase the efficiency of energy use and lower the environmental pollution.

The evaluation of energy-saving building programs can be regarded as an MCDM problem, because it includes multiple criteria in terms of technology, economy, and

${ }^{*}$ Corresponding author. E-mail: liaohuchang@163.com 
environment, and there may be conflicts between them. MCDM methods embody high efficiency and practicability in dealing with decision-making problems in the field of building sustainable development. The typical MCDM methods include the Elimination and choice expressing reality (ELECTRE) (Yu et al., 2018), Technique for order of preference by similarity to ideal solution (TOPSIS) (Chen \& Tsao, 2008), Vise Kriterijumska Optimizacija I Kompromisno Resenje (VIKOR) (Sanayei et al., 2010), and Analytic hierarchy process (AHP) (Vaidya \& Kumar, 2006). At present, the applications of MCDM methods in the building sustainable development mainly focused on green building technology evaluation (Si et al., 2016), green building material selection (Mathiyazhagan et al., 2019; Khoshnava et al., 2018), and sustainable building program evaluation (Heravi et al., 2017; Chen \& Pan, 2016). For example, Si et al. (2016) applied MCDM methods to green technology selection for building renovation, in which the criteria weights and the relative performance scores of green technologies were derived by AHP. Mathiyazhagan et al. (2019) introduced a hybrid MCDM method combining the BWM and TOPSIS for sustainable building material evaluation.

The BWM (Rezaei, 2015) is a new MCDM method to determine the weights of criteria. Compared with AHP, the BWM has simpler operation and higher consistency (Rezaei, 2016). The core step of the BWM is to compare the best and worst criteria with the other criteria respectively to get preference vectors, and then build an optimization model according to the consistency conditions (Mi et al., 2019). If there are $n$ criteria, the number of pairwise comparisons needed in the BWM is $2 n-3$, while in AHP is $n(n-1) / 2$. In addition, the WASPAS (Zavadskas et al., 2012) is a method to integrate the evaluation values of alternatives and then get the final ranking of them. The BWM and WASPAS method are suitable for solving the problem of energy-saving building program selection.

The intuitionistic fuzzy set (IFS) (Atanassov, 1986), which expresses the decision information from membership and non-membership aspects, is a good tool for deal with ambiguity. Yager (2014) extended the IFS theory and defined Pythagorean fuzzy set (PFS), which can better represent the ambiguity. In a PFS, the following conditions must be satisfied that the sum of squares of membership and non-membership degrees is no more than 1. However, in the actual situation, experts may have difficulty in expressing membership and non-membership with exact numbers, while language is a better way for expression. In this regard, the concept of linguistic Pythagorean fuzzy set (LPFS) was introduced (Garg, 2018) to adapt to the complicated decision circumstance in which linguistic terms are used to represent decision information. The use of LPFS can express the uncertainty in the evaluation process of energy-saving building schemes and improve the evaluation accuracy.

Motivated by the above analysis, this paper aims to develop an integrated MCDM method integrating the ex- tended BWM and WASPAS method to handle the energy-saving building program selection problem in the LPF environment. The highlights of this study lie in:

1) The application steps of the BWM method under the LPF environment are proposed. To this point, the criteria weights and the uncertainty in the determination process are considered and the integrity of evaluation information is improved.

2) The calculation steps of the WASPAS method using LFPSs as evaluation information are given, which can improve the accuracy of alternatives sequencing.

3) We develop an MCDM model based on the extended BWM and WASPAS method under the LPF environment, and then apply it to the evaluation of energy-saving building programs to verify the performance of this method in practice.

The paper is structured as follows: Section 1 reviews the current research status of energy-saving buildings, the basic concepts of LPFS and the steps of the original BWM and WASPAS method. In Section 2, the BWM and WASPAS method are extended into LPF environment, and the procedure of the proposed multi-expert MCDM method is introduced. In Section 3, a case study of energy-saving building program evaluation is given to verify the practicability of the method, and in Section 4 a sensitivity analysis is given. Final section draws some conclusions.

\section{Preliminaries}

In this section, we review the researches on energy-saving buildings, and then briefly introduce the basic concepts of LPFS and the steps of the original BWM and WASPAS method.

\subsection{Literature review on energy-saving buildings}

The core idea of energy-saving buildings is to reduce the building energy use and improve the energy use efficiency. The application of energy-saving technology is conductive to reducing the building energy consumption. Some scholars have conducted the research on the performance evaluation of energy-saving technology, and analyzed its energy-saving effect in the actual application. For instance, Kim (2017) analyzed the performance of different energysaving technologies in reducing energy cost saving based on the idea of economic analysis. Geng et al. (2015) established an assessment framework based on the fuzzy AHP, and carried out the suitability evaluation of energy-saving technologies. Lu et al. (2018) introduced a pre-evaluation system based on the TOPSIS and SA (simulated annealing) to evaluate energy-saving technologies during the architectural design phase.

As the performance of building materials has a direct impact on building energy efficiency, some researches on the evaluation of building materials were carried out. Bribian et al. (2011) used the life cycle assessment method 
to make a comparative analysis of common building materials and ecological materials, and analyzed the impact of building materials on energy and environment, so as to provide a reference basis for selecting building materials. Lee et al. (2011) studied the influence of materials on the building's embodied energy to better control the energy demand of buildings in the whole life cycle.

Some scholars have studied on the practical performance of energy-saving buildings, mainly taking the specific energy consumption of heating, lighting, refrigeration, ventilation and other aspects as evaluation criteria (Harish \& Kumar, 2016). Liu et al. (2018) proposed a new building energy efficiency index which was derived based on outdoor temperature to evaluate actual energy-saving effect of building envelops. Delgarm et al. (2016) developed an optimization procedure based on the particle swarm optimization, and applied it to building energy performance evaluation and optimization. To satisfy the needs of sustainable development, energy-saving buildings also need to consider social, economic, technologi$\mathrm{cal}$, institutional and environmental sustainability (Danish et al., 2019). In this sense, the sustainability should be fully considered in the design stage of energy-saving buildings.

\subsection{Linguistic Pythagorean fuzzy set (LPFS)}

To better model the uncertainties faced in decisionmaking process, Yager (2014) proposed the PFS, in which both membership and non-membership degrees are expressed numerically. However, in many practical situations, decision-makers (DMs) may have difficulty in quantifying their preferences with precise values due to the ambiguity of decision information. Using linguistic variables to express membership and non-membership degree can solve this problem. In this regard, Garg (2018) proposed the concept of LPFS. Suppose that $X$ is a universe set and $S_{[0, t]}$ is a continuous linguistic term set with $S_{[0, t]}=\left\{s_{\alpha} \mid s_{0} \leq s_{\alpha} \leq s_{t}, \alpha \in[0, t]\right\}$. An LPFS in $X$ is defined as $L=\left\{\left(x, s_{\sigma}(x), s_{\tau}(x)\right) \mid x \in X\right\}$, where $s_{\sigma}(x), s_{\tau}(x) \in S_{[0, t]}$ represent the degrees of linguistic membership and linguistic non-membership of any element $x$ to set $L$, respectively. Garg (2018) called the pair $\left(s_{\sigma}(x), s_{\tau}(x)\right)$ a linguistic Pythagorean fuzzy number (LPFN), and simply represented it as $\beta=\left(s_{\sigma}, s_{\tau}\right)$. For any $x \in X$, it always holds that $\sigma^{2}+\tau^{2} \leq 1$. $\pi(x)=s \sqrt{t^{2}-\sigma^{2}-\tau^{2}}$ represents the degree of linguistic indeterminacy of $x$ to $L$. The functions of calculating the score and accuracy of the LPFN $\beta$ were respectively defined as (Garg, 2018):

$$
\begin{aligned}
& S(\beta)=\sqrt[s]{\left(t^{2}+\sigma^{2}-\tau^{2}\right) / 2} ; \\
& H(\beta)=\sqrt[s]{\sigma^{2}+\tau^{2}} .
\end{aligned}
$$

According to the above two functions, the comparison rules of two LIFNs $\beta_{1}=\left(s_{\sigma_{1}}, s_{\tau_{1}}\right)$ and $\beta_{2}=\left(s_{\sigma_{2}}, s_{\tau_{2}}\right)$ can be given as below: (1) if $S\left(\beta_{1}\right)>S\left(\beta_{2}\right)$, it means that $\beta_{1}$ is preferred to $\beta_{2}$, and represented as $\beta_{1} \succ \beta_{2}$; (2) if $S\left(\beta_{1}\right)=S\left(\beta_{2}\right)$, then if $H\left(\beta_{1}\right)>H\left(\beta_{2}\right)$, it means that $\beta_{1}$ is preferred to $\beta_{2}$, and represented as $\beta_{1} \succ \beta_{2}$; if $H\left(\beta_{1}\right)=H\left(\beta_{2}\right)$, then it can been considered that $\beta_{1}$ and $\beta_{2}$ indicate the same preference, which is represented as $\beta_{1}=\beta_{2}$. For example, suppose that there are three LPFNs $\beta_{1}=\left(s_{5}, s_{1}\right), \beta_{2}=\left(s_{6}, s_{0}\right), \beta_{3}=\left(s_{5}, s_{2}\right) \in S_{[0,6]}$. We can obtain that $S\left(\beta_{1}\right)=s_{\sqrt{30}}, S\left(\beta_{2}\right)=s_{6}, S\left(\beta_{3}\right)=s_{\sqrt{28.5}}$. According to the above comparison rules, we can conclude that $\beta_{2} \succ$ $\beta_{1} \succ \beta_{3}$.

For two LPFNs $\beta_{1}=\left(s_{\sigma_{1}}, s_{\tau_{1}}\right)$ and $\beta_{2}=\left(s_{\sigma_{2}}, s_{\tau_{2}}\right)$, some basic operations were defined as follows (Garg, 2018):

$$
\begin{aligned}
& \beta_{1} \oplus \beta_{2}=\left(s_{t \sqrt{\sigma_{1}^{2} / t^{2}+\sigma_{2}^{2} / t^{2}-\sigma_{1}^{2} \sigma_{2}^{2} / t^{4}}}, s_{t\left(\tau_{1} \tau_{2} / t^{2}\right)}\right) ; \\
& \lambda \beta_{1}=\left(s_{t \sqrt{1-\left(1-\sigma_{1}^{2} / t^{2}\right)^{\lambda}}}, s_{t\left(\tau_{1} / t\right)^{\lambda}}\right) .
\end{aligned}
$$

To aggregate different LPFNs, some aggregation operators were proposed. Let $\beta_{i}=\left(s_{\sigma_{i}}, s_{\tau_{i}}\right) \in S_{[0, t]}(i=1,2, \cdots, n)$ and $w_{i}$ be the weight of $\beta_{i}$ with $w_{i} \in[0,1]$ and $\sum_{i=1}^{n} w_{i}=1$. Then, the linguistic Pythagorean fuzzy weighted averaging (LPFWA) operator was defined as (Garg, 2018):

$$
\begin{aligned}
& L P F W A_{w}\left(\beta_{1}, \beta_{2}, \cdots, \beta_{n}\right)=\oplus_{i=1}^{n}\left(w_{i} \beta_{i}\right)= \\
& \left(s \sqrt{\left(1-\prod_{i=1}^{n}\left(1-\sigma_{i}^{2} / t^{2}\right)^{w_{i}}\right.}, s \prod_{i=1}^{n}\left(\tau_{i} / t\right)^{w_{i}}\right) .
\end{aligned}
$$

The linguistic Pythagorean fuzzy weighted geometric (LPFWG) operator was defined as (Garg, 2018):

$$
\begin{aligned}
& L P F W G_{w}\left(\beta_{1}, \beta_{2}, \cdots, \beta_{n}\right)=\otimes_{i=1}^{n}\left(\beta_{i}\right)^{w_{i}}= \\
& \left(s \prod_{i=1}^{n}\left(\sigma_{i} / t\right)^{w_{i}}, s \sqrt[t]{\left(1-\prod_{i=1}^{n}\left(1-\tau_{i}^{2} / t^{2}\right)^{w_{i}}\right.}\right) .
\end{aligned}
$$

To convert linguistic terms into numerical values, scholars (Wang et al., 2014; Liao et al., 2019) have studied the numerical conversion scale of linguistic terms. The linguistic scale functions (LSFs), which can use data effectively and express semantics flexibly, and convert linguistic terms into numerical values in different situations. Suppose that $S=\left\{s_{i} \mid i=0,1, \cdots, t\right\}$ is a discrete set of linguistic terms with $t$ being an even number. If $\theta_{i}$ is a numerical value between 0 and 1 , then an LSF is defined as a mapping $f: s_{i} \rightarrow \theta_{i}$ where $0 \leq \theta_{0}<\theta_{1}<\cdots<\theta_{t}(i=0,1, \cdots, t)$. $f$ is a monotonic incremental function. $\theta_{i}$ represents the preferences of DMs when they use the linguistic term $s_{i}$. There are three kinds of LSFs. Here we only introduce the first one as an example:

$$
f\left(s_{i}\right)=\theta_{i}=\frac{i}{t}, \text { where } i=0,1, \cdots, t .
$$

In this way, the linguistic evaluation information can be transformed into evenly divided values. Because of its simplicity and operability, this function is often used in typical decision environments (Wang et al., 2014; Liao et al., 2019). 


\subsection{The best worst method (BWM)}

The BWM (Rezaei, 2015) is a new MCDM method based on programming model. Scholars have studied the BWM and extended it to uncertain environments to solve practical MCDM problems. The latest review of the BWM can be found in Mi et al. (2019). After the original BWM was proposed, Guo and Zhao (2017) extended it to the fuzzy BWM in which the reference comparisons were expressed in triangular fuzzy numbers. Mou et al. (2016) proposed the intuitionistic fuzzy multiplicative BWM and used it for multi-criteria group decision making. Mou et al. (2017) also investigated the intuitionistic fuzzy BWM combined with graph theory. Liu et al. (2019) developed an extended BWM in interval-valued intuitionistic uncertain linguistic environment and used it to solve sustainable supplier selection problem. Mi and Liao (2019) extended the BWM to deal with preference information expressed in hesitant fuzzy numbers and developed three different models under different situations to compute the criteria weights. $\mathrm{Li}$ et al. (2019) introduced a new MCDM approach for the selection problem of best investment company, which combined the BWM and dominance degree to process probabilistic fuzzy information.

In the BWM, the weights of criteria can be derived through pairwise comparisons. And the BWM performs fewer pairwise comparisons and has higher consistency degree than AHP. First, the BWM obtains two preference vectors by determining the best and worst criteria and comparing them with other criteria respectively. On this basis, a model based on preference information consistency is set up to obtain the weights of criteria. The main steps of the BWM are shown below (Rezaei, 2015).

Step 1. Construct the set of criteria $\left\{c_{1}, c_{2}, \cdots, c_{n}\right\}$ based on the decision objectives.

Step 2. Determine the best and worst criteria, expressed as $c_{B}$ and $c_{W}$, respectively.

Step 3. Implement pairwise comparisons between the best criterion and the other criteria. The preferences of the best criterion on the other criteria are hereinafter simply expressed as "the preferences of best-to-others", which are represented by numbers between 1 and 9 . And the preference vector of best-to-others (BO) is denoted as $V_{B}=\left(v_{B 1}, v_{B 2}, \cdots, v_{B n}\right)$.

Step 4. Implement pairwise comparisons between the other criteria and the worst criterion. The preferences of the other criteria on the worst criterion are hereinafter simply expressed as "the preferences of others-to-worst", which are represented by numbers between 1 and 9 . And the preference vector of others-to-worst $(\mathrm{OW})$ is denoted as $V_{W}=\left(v_{1 W}, v_{2 W}, \cdots, v_{n W}\right)^{T}$.

Step 5. Establish an optimization model according to the consistency conditions. When the preference information is completely consistent, the conditions of $w_{B} / w_{j}=v_{B j}$ and $w_{j} / w_{W}=v_{j W}$ are satisfied. To get the optimal weights, the following model is built, which aims to minimize the maximum values of $\left|w_{B} / w_{j}-v_{B j}\right|$ and $\left|w_{j} / w_{W}-v_{j W}\right|$ for all criteria.

\section{Model 1}

$$
\begin{aligned}
& \min \xi \\
& \text { s.t. } \\
& \mid \begin{array}{l}
w_{B} / w_{j}-v_{B j} \mid \leq \xi, j=1,2, \cdots, n \\
w_{j} / w_{W}-v_{j W} \mid \leq \xi, j=1,2, \cdots, n, \\
\sum_{j} w_{j}=1 \\
w_{j} \geq 0, j=1,2, \cdots, n
\end{array}
\end{aligned}
$$

where $\xi=\underset{j}{\max }\left\{\left|w_{B} / w_{j}-v_{B j}\right|,\left|w_{j} / w_{W}-v_{j W}\right|\right\}$.

Solving Model 1 , the optimal weights $\left(w_{1}^{*}, w_{2}^{*}, \cdots, w_{n}^{*}\right)$ and the maximum absolute difference $\xi^{*}$ are obtained.

Based on the ideas of Rezaei (2016), if we minimize the maximum of $\left\{\left|w_{B}-v_{B j} w_{j}\right|,\left|w_{j}-v_{j W} w_{W}\right|\right\}$ instead of the maximum $\left|w_{B} / w_{j}-v_{B j}\right|$ and $\left|w_{j} / w_{W}-v_{j W}\right|$, Model 1 will be transformed into a linear optimization model as shown below:

\section{Model 2}

$$
\begin{aligned}
& \min \xi^{L} \\
& \text { s.t. } \\
& \mid \begin{array}{l}
w_{B}-v_{B j} w_{j} \mid \leq \xi^{L}, j=1,2, \cdots, n \\
w_{j}-v_{j W} w_{W} \mid \leq \xi^{L}, j=1,2, \cdots, n,
\end{array} \\
& \sum_{j} w_{j}=1 \\
& w_{j} \geq 0, j=1,2, \cdots, n \\
& \text { where } \xi^{L}=\max \left\{\left|w_{B}-v_{B j} w_{j}\right|,\left|w_{j}-v_{j W} w_{W}\right|\right\} .
\end{aligned}
$$

There is a unique solution of Model 2, that is the weights of criteria $\left(w_{1}^{*}, w_{2}^{*}, \cdots, w_{n}^{*}\right)$ and $\xi^{L^{*}}$. $\xi^{L^{*}}$ can be regarded as the consistency indicator directly, and the value of $\xi^{L^{*}}$ is closer to 0 , it represents a higher level of consistency. In this study, Model 2 is selected to calculate the weights of criteria.

\subsection{The Weighted Aggregated Sum Product Assessment (WASPAS) method}

The WASPAS method is an MCDM method developed in 2012. By combining the weighted sum model (WSM) and weighted product model (WPM), it can significantly improve the ranking accuracy and thus has been applied in many fields for solving actual MCDM problems. Turskis et al. (2015) combined the WASPAS and AHP with fuzzy values, and presented a hybrid model to solve construction site selection problem. Keshavarz Ghorabaee et al. (2016) introduced an integrated MCDM approach based on the WASPAS method for supplier selection problem with interval type-2 fuzzy set (IT2FS). Deveci et al. (2018) introduced a hybrid MCDM method with IT2FS to solve the problem of car sharing station selection, which integrated the WASPAS with the TOPSIS. Mishra and Rani (2018) developed an MCDM approach by extending the 
WASPAS method into interval-valued intuitionistic fuzzy environment, and used it into a case of flood control management. Ren et al. (2019) developed a SWARA-WASPAS approach with hesitant fuzzy linguistic information and applied it for the site selection of electric vehicle charging station.

For an MCDM problem, suppose that $x_{i j}$ represents the performance value of the alterative $A_{i}$ with regard to the criterion $c_{j}$, and $w_{j}$ represents the relative importance of the criterion $c_{j}$. The steps for evaluating alternatives using the WASPAS method are as follows (Zavadskas et al., 2012):

Step 1. Normalize performance values in the following way:

for beneficial criteria, the normalized values $\bar{x}_{i j}$ are computed by

$$
\bar{x}_{i j}=\frac{x_{i j}}{\max _{i} x_{i j}}
$$

for non-beneficial criteria, then,

$$
\bar{x}_{i j}=\frac{\min _{i} x_{i j}}{x_{i j}} .
$$

Step 2. Compute the values of WSM, $Q_{i}^{1}=\sum_{j=1}^{m} w_{j} \bar{x}_{i j}$ and WPM, $Q_{i}^{2}=\prod_{j=1}^{m}\left(\bar{x}_{i j}\right)^{w_{j}}$, for each alternative.

Step 3. Compute the aggregated measure $Q_{i}=\lambda Q_{i}^{1}+$ $(1-\lambda) Q_{i}^{2}$ of the WASPAS method for each alternative where $\lambda \in[0,1]$ is the parameter of the WASPAS method. When $\lambda=1$, the WASPAS method turns into the WSM, and $\lambda=0$ leads to the WPM.

Step 4. Rank the alternatives in decreasing order of $Q_{i}$.

\section{An integrated method with the extended BWM and WASPAS method under the LPF context}

In many practical situations, decision-making information has strong uncertainty. In order to adapt to more complex decision-making environment, in this section, we extend the original BWM and WASPAS method into the LPF environment, and propose an integrated MCDM method. The LPF-BWM is investigated to compute the weights of criteria, while the LPF-WASPAS method is proposed to obtain the ranking of alternatives.

\subsection{The LPF-BWM}

In the LPF-BWM, experts are supposed to use LPFNs to express preference information for criteria. Firstly, each expert $e_{k}(k=1,2, \cdots, p)$ selects the best and worst criteria from a set of criteria $\left\{c_{1}, c_{2}, \cdots, c_{j}, \cdots, c_{n}\right\}$, which are represented by $c_{B}^{k}$ and $c_{W}^{k}$, respectively.

Then, each expert needs to provide their preferences of best-to-others through making pairwise comparisons. The preferences are expressed in LPFNs, and the LPF-BO vector is obtained as:

$$
\widetilde{V}_{B}^{k}=\left(\tilde{v}_{B 1}^{k}, \tilde{v}_{B 2}^{k}, \cdots, \tilde{v}_{B n}^{k}\right),
$$

where $\tilde{v}_{B j}^{k}$ is an LPFN, which refers to the linguistic fuzzy preference of the best criterion $c_{B}^{k}$ on criterion $c_{j}$ determined by expert $e_{k}$, and $\tilde{v}_{B B}^{k}=\left(s_{4}, s_{4}\right)$. Similarly, each expert provides the preferences of worst-to-others using corresponding LPFNs, and obtains the LPF-OW vector as:

$$
\widetilde{V}_{W}^{k}=\left(\tilde{v}_{1 W}^{k}, \tilde{v}_{2 W}^{k}, \cdots, \tilde{v}_{n W}^{k}\right)^{T},
$$

where $\tilde{v}_{j W}^{k}$ refers to the linguistic fuzzy preference of criterion $c_{j_{\sim}}$ on the worst criterion $c_{W}^{k}$ determined by expert $e_{k}$, and $v_{W W}=\left(s_{4}, s_{4}\right)$.

Next, the preference vectors are transformed using the score function and LSFs. Since the score function can indicates the extent to which the alternative meets the requirements of decision-maker (Chen \& Tan, 1994), the score function given as Eqn (1) can represent the preference degrees of experts in pairwise comparisons. Therefore, the LPF-BO vector and LPF-OW vector are transformed into the following forms, respectively:

$$
\begin{aligned}
& S\left(\widetilde{V}_{B}^{k}\right)=\left(S\left(\tilde{v}_{B 1}^{k}\right), S\left(\tilde{v}_{B 2}^{k}\right), \cdots, S\left(\tilde{v}_{B n}^{k}\right)\right) ; \\
& S\left(\widetilde{V}_{W}^{k}\right)=\left(S\left(\tilde{v}_{1 W}^{k}\right), S\left(\tilde{v}_{2 W}^{k}\right), \cdots, S\left(\tilde{v}_{n W}^{k}\right)\right)^{T} .
\end{aligned}
$$

Afterwards, the LSF given as Eqn (7) is used to further convert the linguistic terms into numerical values. Then, the final LPF-BO vector and LPF-OW vector can be respectively deduced as:

$$
\begin{aligned}
& f\left(S\left(\widetilde{V}_{B}^{k}\right)\right)=\left(f\left(S\left(\tilde{v}_{B 1}^{k}\right)\right), f\left(S\left(\tilde{v}_{B 2}^{k}\right)\right), \cdots, f\left(S\left(\tilde{v}_{B n}^{k}\right)\right)\right) ; \\
& f\left(S\left(\widetilde{V}_{W}^{k}\right)\right)=\left(f\left(S\left(\tilde{v}_{1 W}^{k}\right)\right), f\left(S\left(\tilde{v}_{2 W}^{k}\right)\right), \cdots, f\left(S\left(\tilde{v}_{n W}^{k}\right)\right)\right)^{T} .
\end{aligned}
$$

The relationship between preference degrees and the weights of criteria can be expressed as:

$$
f\left(S\left(\tilde{v}_{B j}^{k}\right)\right)=\frac{w_{B}}{w_{B}+w_{j}}, f\left(S\left(\tilde{v}_{j W}^{k}\right)\right)=\frac{w_{j}}{w_{j}+w_{W}} .
$$
lished:

Finally, for each expert, the following model is estab-

\section{Model 3}

$$
\begin{aligned}
& \min \zeta^{k} \\
& \text { s.t. } \\
& \mid \begin{array}{l}
w_{B}^{k}-f\left(S\left(\tilde{v}_{B j}^{k}\right)\right)\left(w_{B}^{k}+w_{j}^{k}\right) \mid \leq \zeta^{k} \\
w_{j}^{k}-f\left(S\left(\tilde{v}_{j W}^{k}\right)\right)\left(w_{j}^{k}+w_{W}^{k}\right) \mid \leq \zeta^{k} . \\
\sum_{j} w_{j}^{k}=1 \\
w_{j}^{k} \geq 0, j=1,2, \cdots, n, k=1,2, \cdots, p
\end{array}
\end{aligned}
$$

Solving Model 3, the individual optimal weights $\left(w_{1}^{k^{*}}, w_{2}^{k^{*}}, \cdots, w_{n}^{k^{*}}\right)$ corresponding to each expert and the consistency indicator $\zeta^{k^{*}}$ are obtained. Then, we can compute the final collective weight of criterion $c_{j}$ by taking the average value as follows:

$$
w_{j}=\sum_{k=1}^{p} w_{j}^{k^{*}} / p, \text { for } j=1,2, \cdots, n .
$$




\subsection{The LPF-WASPAS method}

Experts use LPFNs to evaluate the alternatives, which can better express uncertainty and improve the accuracy of decision-making results. The steps of the LPF-WASPAS method are clarified as follows.

Firstly, experts are required to evaluate the alternatives $A_{i}(i=1,2, \cdots, m)$ according to the criteria set $\left\{c_{1}, c_{2}, \cdots, c_{j}, \cdots, c_{n}\right\}$, and then the LPF decision matrices are obtained as:

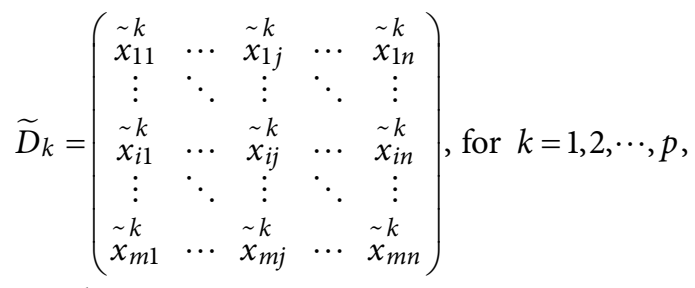

where $\tilde{x}_{i j}^{k}=\left(s_{\sigma_{i j}}, s_{\tau_{i j}}\right)$ is a LPFN, indicating the performance value of the alternative $A_{i}$ on the criterion $c_{j}$ provided by expert $e_{k}$.

Then, we standardize the LPFNs in $\widetilde{D}_{k}$ and get the normalized LPF decision matrices $\overline{\widetilde{D}}_{k}$ as:

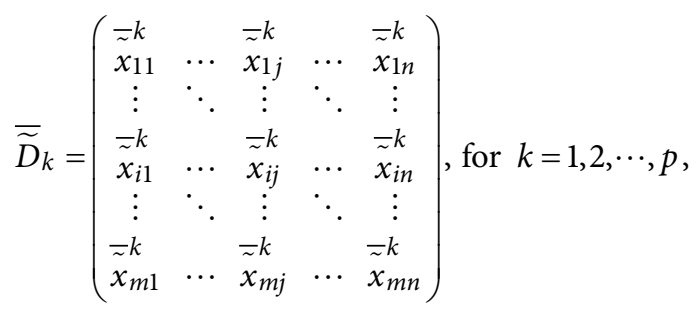

where:

$$
\begin{aligned}
& \bar{\sim}_{i j}^{k}=\left(s_{\sigma_{i j}}, s_{\tau_{i j}}\right), \text { for beneficial criteria; } \\
& \bar{\sim}_{i j}^{k}=\left(s_{\tau_{i j}}, s_{\sigma_{i j}}\right), \text { for non-beneficial criteria. }
\end{aligned}
$$

Next, according to the relative importance of experts $\lambda_{k}(k=1,2, \cdots, p)$, we utilize the LPFWA operator to integrate all the experts' evaluation information into an aggregated decision matrix $\widetilde{D}$ as:

$$
\widetilde{D}=\left(\begin{array}{ccccc}
\tilde{x}_{11} & \cdots & \tilde{x}_{1 j} & \cdots & \tilde{x}_{1 n} \\
\vdots & \ddots & \vdots & \ddots & \vdots \\
\tilde{x}_{i 1} & \cdots & \tilde{x}_{i j} & \cdots & \tilde{x}_{i n} \\
\vdots & \ddots & \vdots & \ddots & \vdots \\
\tilde{x}_{m 1} & \cdots & \tilde{x}_{m j}^{k} & \cdots & \tilde{x}_{m n}
\end{array}\right),
$$

where

$$
\begin{aligned}
& \tilde{x}_{i j}=L P F W A_{\lambda}\left(\overline{\tilde{x}}_{i j}^{1}, \overline{\tilde{x}}_{i j}^{2}, \cdots, \overline{\tilde{x}_{i j}^{p}}\right)=\oplus_{k=1}^{p}\left(\lambda_{k} \overline{\tilde{x}}_{i j}^{k}\right)= \\
& \left(s \sqrt[t]{\left(1-\prod_{k=1}^{p}\left(1-\sigma_{i j}^{2} / t^{2}\right)^{\lambda_{k}}\right.}, s \prod_{k=1}^{p}\left(\tau_{i j} / t\right)^{\lambda_{k}}\right) .
\end{aligned}
$$

Afterwards, combining the weights of criteria, $\left\{w_{1}, w_{2}\right.$, $\left.\cdots, w_{n}\right\}$, we can compute the values of the WSM $\left(Q_{i}^{1}\right)$ and the WPM $\left(Q_{i}^{2}\right)$ for each alternative by Eqn (21) and Eqn (22), respectively:

$$
\begin{aligned}
& Q_{i}^{1}=L P F W A_{w}\left(\tilde{x}_{i 1}, \tilde{x}_{i 2}, \cdots, \tilde{x}_{i n}\right)= \\
& \left(s \sqrt{\left(1-\prod_{j=1}^{n}\left(1-\sigma_{i j}^{2} / t^{2}\right)^{w_{j}}\right.}, s \prod_{j=1}^{n}\left(\tau_{i j} / t\right)^{w_{j}}\right) ; \\
& Q_{i}^{2}=L P F W G_{w}\left(\tilde{x}_{i 1}, \tilde{x}_{i 2}, \cdots, \tilde{x}_{i n}\right)= \\
& \left(s \prod_{j=1}^{n}\left(\sigma_{i j} / t\right)^{w_{j}}, \sqrt[s]{\left(1-\prod_{j=1}^{n}\left(1-\tau_{i j}^{2} / t^{2}\right)^{w_{j}}\right.}\right) .
\end{aligned}
$$

Finally, we compute the evaluation value $Q_{i}$ of each alternative and rank the alternatives:

$$
Q_{i}=\lambda Q_{i}^{1}+(1-\lambda) Q_{i}^{2} \text {. }
$$

\subsection{Procedure of the LPF-BWM-WASPAS method}

This subsection presents an integrated multi-experts MCDM method combing the LPF-BWM and the LPFWASPAS method. To better illustrate the application process of the proposed method, the main steps are briefly shown as below.

Step 1. Set up a decision-making committee composed of multiple experts $\left\{e_{1}, e_{2}, \cdots, e_{k}, \cdots, e_{p}\right\}$. Define the objectives of the decision-making problem and determine the criteria set $\left\{c_{1}, c_{2}, \cdots, c_{j}, \cdots, c_{n}\right\}$ and alternative set $\left\{A_{1}, A_{2}, \cdots, A_{i}, \cdots, A_{m}\right\}$.

Step 2. Identify the best criterion $c_{B}^{k}$ and the worst criterion $c_{W}^{k}$, and obtain the LPF-BO and LPF-OW vectors of each experts by making pairwise comparisons.

Step 3. Convert the LPFNs in the preference vectors to crisp numbers using the score function and the LSF, and obtain the individual optimal weights $\left(w_{1}^{k^{*}}, w_{2}^{k^{*}}, \cdots, w_{n}^{k^{*}}\right)$ corresponding to each expert and the consistency indicator $\zeta^{k^{*}}$ by Model 3. If the acceptable consistency is met, the next step is taken. Otherwise, a reevaluation step is needed.

Step 4. Compute the final collective weights of criteria by Eqn (17).

Step 5. The LPF decision matrix of each expert is obtained and standardized. Then, according to the weights of experts, obtain the aggregated LPF decision matrix by Eqn (20).

Step 6. Compute the aggregated measure of the LPF-WASPAS method for each alternative by Eqns (21)-(23), and get the whole ranking of alternatives.

In the above steps, Steps 2-4 belong to the LPF-BWM, which is used for computing the weights of criteria. In Step 3, experts use LPFNs to express their preferences. Then, the linguistic preference information is converted to numerical values based on the score function and the LSF. Steps 4-6 belong to the LPF-WASPAS method, which are the process of determining the ranking of alternatives. Using the above procedure, we can solve multi-experts MCDM problems under the LPF environment. 


\section{Case study: an evaluation of energy-saving building programs}

In this section, we present a case study on the evaluation of energy-saving building programs, and the LPF-BWMWASPAS method is utilized to solve this case. Then, a sensitivity analysis is further implemented to illustrate the reliability and practicability of this method.

\subsection{Case description}

With the rapid economic and social development, the construction industry is expanding rapidly, and the demand for construction is increasing. Building energy consumption is also showing an increasing trend. In China, energy consumption in construction industry accounted for a large proportion of all industries, reaching $20 \%$ in 2015, with Chinas further urbanization and industrialization, China's building energy consumption will continue to increase (Wang et al., 2019). Because of the huge energy consumption in the construction industry, building energy conservation has become a trend of the construction industry. China has already begun to promote energysaving buildings.

Company B is a real estate enterprise and one of the top 10 real estate development enterprises in China. Its main business includes real estate development, commercial operation, and intelligent service. The Company $B$ intends to develop a new project in Chengdu, China, to build a residential community. Because Chengdu is very hot in summer, cold and humid in winter, and the temperature changes dramatically, and thus residents use air conditioning appliances frequently. In response to the strategy of sustainable development, the energy-saving building is considered in this project. To maximize the benefits and meet the requirements of building energy conservation, the Company B requires the design unit to provide different alternatives. Among all the alternatives, the optimum program which meets the requirements of economy, energy consumption and usability is selected as the final design program. Now there are three alternatives $A_{i}(i=1,2,3)$ to choose from, and the Company B invites four experts $e_{k}(k=1,2,3,4)$ from construction-related specialties to form a decision-making committee to evaluate the alternatives. Due to the different working years and professional titles of each expert, the relative importance of the experts is given as $\{0.3,0.2,0.4,0.1\}$. According to the meaning of energy-saving buildings and the objectives of this project, the evaluation criteria are determined from three dimensions: economy, usability and environment. The specific criteria are presented in Table 1.

Among these criteria, the construction cost $\left(c_{1}\right)$ refers the direct cost of the project, and the internal rate of return $\left(c_{2}\right)$ reflects the profitability and risk resistance of the project. The functional rationality $\left(c_{3}\right)$ refers to the degree to which the building meets the living needs of residents and whether the functional zoning is reasonable or not. The maintainability $\left(c_{4}\right)$ is the ease of carry-
Table 1. Evaluation criteria of energy-saving building programs

\begin{tabular}{|l|l|l|}
\hline \multirow{2}{*}{ Dimension } & \multicolumn{1}{|c|}{ Criterion } & \multicolumn{1}{|c|}{$\begin{array}{c}\text { Type of the } \\
\text { criterion }\end{array}$} \\
\hline \multirow{5}{*}{ Economy } & Construction cost $\left(c_{1}\right)$ & Non-beneficial \\
\cline { 2 - 3 } & Internal rate of return $\left(c_{2}\right)$ & Beneficial \\
\hline \multirow{5}{*}{ Esability } & Functional rationality $\left(c_{3}\right)$ & Beneficial \\
\cline { 2 - 3 } & Maintainability $\left(c_{4}\right)$ & Beneficial \\
\cline { 2 - 3 } & Comfort $\left(c_{5}\right)$ & Beneficial \\
\cline { 2 - 3 } & Safety $\left(c_{6}\right)$ & Beneficial \\
\hline & Sustainability $\left(c_{7}\right)$ & Beneficial \\
\cline { 2 - 3 } & $\begin{array}{l}\text { Performance of building } \\
\text { materials }\left(c_{8}\right)\end{array}$ & Beneficial \\
\cline { 2 - 3 } & $\begin{array}{l}\text { Application of energy-saving } \\
\text { technology }\left(c_{9}\right)\end{array}$ & Beneficial \\
\cline { 2 - 3 } & $\begin{array}{l}\text { Building energy consumption } \\
\text { level }\left(c_{10}\right)\end{array}$ & Non-beneficial \\
\hline
\end{tabular}

ing out the later maintenance work of the building. The comfort $\left(c_{5}\right)$ refers to the satisfaction of living. The safety $\left(c_{6}\right)$ includes structural safety and environmental safety. The sustainability $\left(c_{7}\right)$ is the application degree of sustainable concept in architectural design. The performance of building materials $\left(c_{8}\right)$ is the basic performance of building materials involved in design programs. The application of energy-saving technology $\left(c_{9}\right)$ refers to the suitability of energy-saving technologies used in the program, and the estimated energy-saving effect. The building energy consumption level $\left(c_{10}\right)$ refers to the estimated annual building energy consumption of the program.

\subsection{Select the optimal program by the LPF-BWM-WASPAS method}

To select the optimal energy-saving program, the alternatives are evaluated by the LPF-BWM-WASPAS method. The specific procedure is shown below.

In the evaluation process, experts provide their preferences for alternatives and criteria with the following linguistic term set $S$ :

$S=\left\{\begin{array}{l}s_{0}=\text { extremely bad, } s_{1}=\text { very bad, } s_{2}=\text { bad } \\ s_{3}=\text { medium bad, } s_{4}=\text { medium, } s_{5}=\text { medium good, } \\ s_{6}=\text { good, } s_{7}=\text { very good, } s_{8}=\text { extremely good }\end{array}\right\}$.

Step 1. As shown above, the decision-making committee, criteria and alternatives are determined.

Step 2. Each expert selects the best and worst criteria based on his own experience and opinions, and uses LPFNs to determine the preferences in pairwise comparisons. The linguistic fuzzy preferences provided by each expert are collected in Tables 2 and 3.

Step 3. Using the score function of LPFNs and the LSF of linguistic terms given as Eqn (7), the preferences of experts are converted into crisp numbers, as shown in Tables 4 and 5. 
Table 2. Linguistic fuzzy preferences of best-to-others

\begin{tabular}{|c|c|c|c|c|c|c|c|c|c|c|c|}
\hline \multirow{2}{*}{ Expert } & \multirow{2}{*}{$\begin{array}{c}\text { Best } \\
\text { criterion }\end{array}$} & \multicolumn{10}{|c|}{ Other criteria } \\
\hline & & $c_{1}$ & $c_{2}$ & $c_{3}$ & $c_{4}$ & $c_{5}$ & $c_{6}$ & $c_{7}$ & $c_{8}$ & $c_{9}$ & $c_{10}$ \\
\hline$e_{1}$ & $c_{10}$ & $\left(s_{7}, s_{3}\right)$ & $\left(s_{6}, s_{3}\right)$ & $\left(s_{8}, s_{4}\right)$ & $\left(s_{8}, s_{0}\right)$ & $\left(s_{7}, s_{5}\right)$ & $\left(s_{6}, s_{4}\right)$ & $\left(s_{4}, s_{2}\right)$ & $\left(s_{5}, s_{4}\right)$ & $\left(s_{6}, s_{5}\right)$ & $\left(s_{4}, s_{4}\right)$ \\
\hline$e_{2}$ & $c_{7}$ & $\left(s_{8}, s_{0}\right)$ & $\left(s_{6}, s_{3}\right)$ & $\left(s_{7}, s_{3}\right)$ & $\left(s_{6}, s_{2}\right)$ & $\left(s_{6}, s_{3}\right)$ & $\left(s_{5}, s_{4}\right)$ & $\left(s_{4}, s_{4}\right)$ & $\left(s_{5}, s_{3}\right)$ & $\left(s_{5}, s_{4}\right)$ & $\left(s_{6}, s_{5}\right)$ \\
\hline$e_{3}$ & $c_{9}$ & $\left(s_{7}, s_{2}\right)$ & $\left(s_{6}, s_{3}\right)$ & $\left(s_{8}, s_{0}\right)$ & $\left(s_{7}, s_{2}\right)$ & $\left(s_{5}, s_{3}\right)$ & $\left(s_{6}, s_{1}\right)$ & $\left(s_{4}, s_{2}\right)$ & $\left(s_{5}, s_{3}\right)$ & $\left(s_{4}, s_{4}\right)$ & $\left(s_{5}, s_{4}\right)$ \\
\hline$e_{4}$ & $c_{10}$ & $\left(s_{7}, s_{2}\right)$ & $\left(s_{6}, s_{1}\right)$ & $\left(s_{5}, s_{1}\right)$ & $\left(s_{6}, s_{2}\right)$ & $\left(s_{8}, s_{0}\right)$ & $\left(s_{5}, s_{4}\right)$ & $\left(s_{4}, s_{2}\right)$ & $\left(s_{5}, s_{3}\right)$ & $\left(s_{5}, s_{4}\right)$ & $\left(s_{4}, s_{4}\right)$ \\
\hline
\end{tabular}

Table 3. Linguistic fuzzy preferences of others-to-worst

\begin{tabular}{|c|c|c|c|c|c|c|c|c|c|c|c|}
\hline \multirow{2}{*}{ Expert } & \multirow{2}{*}{$\begin{array}{l}\text { Worst } \\
\text { criterion }\end{array}$} & \multicolumn{10}{|c|}{ Other criteria } \\
\hline & & $c_{1}$ & $c_{2}$ & $c_{3}$ & $c_{4}$ & $c_{5}$ & $c_{6}$ & $c_{7}$ & $c_{8}$ & $c_{9}$ & $c_{10}$ \\
\hline$e_{1}$ & $c_{4}$ & $\left(s_{5}, s_{3}\right)$ & $\left(s_{7}, s_{5}\right)$ & $\left(s_{5}, s_{4}\right)$ & $\left(s_{4}, s_{4}\right)$ & $\left(s_{5}, s_{3}\right)$ & $\left(s_{5}, s_{2}\right)$ & $\left(s_{7}, s_{3}\right)$ & $\left(s_{6}, s_{2}\right)$ & $\left(s_{6}, s_{1}\right)$ & $\left(s_{8}, s_{0}\right)$ \\
\hline$e_{2}$ & $c_{1}$ & $\left(s_{4}, s_{4}\right)$ & $\left(s_{6}, s_{3}\right)$ & $\left(s_{5}, s_{3}\right)$ & $\left(s_{7}, s_{5}\right)$ & $\left(s_{6}, s_{4}\right)$ & $\left(s_{5}, s_{3}\right)$ & $\left(s_{8}, s_{0}\right)$ & $\left(s_{8}, s_{4}\right)$ & $\left(s_{7}, s_{2}\right)$ & $\left(s_{6}, s_{1}\right)$ \\
\hline$e_{3}$ & $c_{3}$ & $\left(s_{5}, s_{4}\right)$ & $\left(s_{5}, s_{1}\right)$ & $\left(s_{4}, s_{4}\right)$ & $\left(s_{5}, s_{2}\right)$ & $\left(s_{6}, s_{4}\right)$ & $\left(s_{7}, s_{2}\right)$ & $\left(s_{6}, s_{1}\right)$ & $\left(s_{8}, s_{4}\right)$ & $\left(s_{8}, s_{0}\right)$ & $\left(s_{7}, s_{4}\right)$ \\
\hline$e_{4}$ & $c_{5}$ & $\left(s_{5}, s_{3}\right)$ & $\left(s_{5}, s_{1}\right)$ & $\left(s_{4}, s_{1}\right)$ & $\left(s_{6}, s_{4}\right)$ & $\left(s_{4}, s_{4}\right)$ & $\left(s_{7}, s_{2}\right)$ & $\left(s_{8}, s_{3}\right)$ & $\left(s_{6}, s_{3}\right)$ & $\left(s_{6}, s_{2}\right)$ & $\left(s_{8}, s_{0}\right)$ \\
\hline
\end{tabular}

Table 4. Numerical preferences of best-to-others

\begin{tabular}{|c|c|c|c|c|c|c|c|c|c|c|c|}
\hline \multirow{2}{*}{ Experts } & \multirow{2}{*}{$\begin{array}{c}\text { Best } \\
\text { criterion }\end{array}$} & \multicolumn{10}{|c|}{ Other criteria } \\
\hline & & $c_{1}$ & $c_{2}$ & $c_{3}$ & $c_{4}$ & $c_{5}$ & $c_{6}$ & $c_{7}$ & $c_{8}$ & $c_{9}$ & $c_{10}$ \\
\hline$e_{1}$ & $c_{10}$ & 0.9014 & 0.8432 & 0.9354 & 1 & 0.8292 & 0.8101 & 0.7706 & 0.7552 & 0.7655 & 0.7071 \\
\hline$e_{2}$ & $c_{7}$ & 1 & 0.8432 & 0.9014 & 0.8660 & 0.8432 & 0.7552 & 0.7071 & 0.7906 & 0.7552 & 0.7655 \\
\hline$e_{3}$ & $c_{9}$ & 0.9228 & 0.8432 & 1 & 0.9228 & 0.7906 & 0.8795 & 0.7706 & 0.7906 & 0.7071 & 0.7552 \\
\hline$e_{4}$ & $c_{10}$ & 0.9228 & 0.8795 & 0.8292 & 0.8660 & 1 & 0.7552 & 0.7706 & 0.7906 & 0.7552 & 0.7071 \\
\hline
\end{tabular}

Then, according to Model 3, the optimization models with respect to each expert are set up to compute the individual weights of criteria. Taking expert $e_{1}$ as an example, the following model is established:

\section{Model 4}

$\min \zeta^{1}$

s.t.

$\left|w_{10}^{1}-0.9014\left(w_{10}^{1}+w_{1}^{1}\right)\right| \leq \zeta^{1},\left|w_{10}^{1}-0.8432\left(w_{10}^{1}+w_{2}^{1}\right)\right| \leq \zeta^{1}$

$\left|w_{10}^{1}-0.9354\left(w_{10}^{1}+w_{3}^{1}\right)\right| \leq \zeta^{1},\left|w_{10}^{1}-\left(w_{10}^{1}+w_{4}^{1}\right)\right| \leq \zeta^{1}$

$\left|w_{10}^{1}-0.8292\left(w_{10}^{1}+w_{5}^{1}\right)\right| \leq \zeta^{1},\left|w_{10}^{1}-0.8101\left(w_{10}^{1}+w_{6}^{1}\right)\right| \leq \zeta^{1}$

$\left|w_{10}^{1}-0.7706\left(w_{10}^{1}+w_{7}^{1}\right)\right| \leq \zeta^{1},\left|w_{10}^{1}-0.7552\left(w_{10}^{1}+w_{8}^{1}\right)\right| \leq \zeta^{1}$

$\left|w_{10}^{1}-0.7655\left(w_{10}^{1}+w_{9}^{1}\right)\right| \leq \zeta^{1},\left|w_{1}^{1}-0.7906\left(w_{1}^{1}+w_{4}^{1}\right)\right| \leq \zeta^{1}$

$\left|w_{2}^{1}-0.8292\left(w_{2}^{1}+w_{4}^{1}\right)\right| \leq \zeta^{1},\left|w_{3}^{1}-0.7552\left(w_{3}^{1}+w_{4}^{1}\right)\right| \leq \zeta^{1}$

$\left|w_{5}^{1}-0.7906\left(w_{5}^{1}+w_{4}^{1}\right)\right| \leq \zeta^{1},\left|w_{6}^{1}-0.8149\left(w_{6}^{1}+w_{4}^{1}\right)\right| \leq \zeta^{1}$

$\left|w_{7}^{1}-0.9014\left(w_{7}^{1}+w_{4}^{1}\right)\right| \leq \zeta^{1},\left|w_{8}^{1}-0.8660\left(w_{8}^{1}+w_{4}^{1}\right)\right| \leq \zeta^{1}$

$\left|w_{9}^{1}-0.8795\left(w_{9}^{1}+w_{1}^{1}\right)\right| \leq \zeta^{1}$

$\sum_{j=1}^{10} w_{j}^{1}=1, w_{j}^{1} \geq 0$.

Similarly, we can build optimization models in terms of the other experts. Solving these models by LINGO software, we can get the individual weights of criteria and the corresponding consistency indicator values (see Table 6).
Step 4. Using Eqn (17), the final collective weights of criteria are obtained as $\{0.0403,0.0735,0.0469,0,0494,0.0634$, $0.0913,0.1666,0.1003,0.1335,0.2348\}$.

Step 5. Each expert uses LPFNs to provide the performance values of all the alternatives with regard to every criterion, and the decision matrixes are shown below:

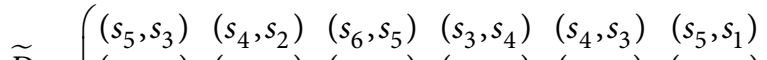

$$
\begin{aligned}
& \widetilde{D}_{1}=\left(\begin{array}{llllll}
\left(s_{6}, s_{4}\right) & \left(s_{4}, s_{3}\right) & \left(s_{3}, s_{2}\right) & \left(s_{5}, s_{4}\right) & \left(s_{6}, s_{1}\right) & \left(s_{4}, s_{3}\right)
\end{array}\right. \\
& \begin{array}{llllll}
\left(s_{4}, s_{3}\right) & \left(s_{3}, s_{2}\right) & \left(s_{7}, s_{5}\right) & \left(s_{5}, s_{3}\right) & \left(s_{4}, s_{2}\right) & \left(s_{5}, s_{4}\right)
\end{array} \\
& \left.\left(s_{6}, s_{3}\right) \quad\left(s_{4}, s_{2}\right) \quad\left(s_{3}, s_{2}\right) \quad\left(s_{6}, s_{4}\right)\right) \\
& \left(s_{3}, s_{1}\right) \quad\left(s_{6}, s_{3}\right) \quad\left(s_{6}, s_{5}\right) \quad\left(s_{4}, s_{3}\right) ; \\
& \left.\left(s_{5}, s_{3}\right) \quad\left(s_{6}, s_{4}\right) \quad\left(s_{4}, s_{2}\right) \quad\left(s_{3}, s_{4}\right)\right) \\
& \widetilde{D}_{2}=\left(\begin{array}{llllll}
\left(s_{4}, s_{5}\right) & \left(s_{5}, s_{2}\right) & \left(s_{2}, s_{3}\right) & \left(s_{6}, s_{1}\right) & \left(s_{4}, s_{3}\right) & \left(s_{7}, s_{4}\right) \\
\left(s_{6}, s_{4}\right) & \left(s_{7}, s_{3}\right) & \left(s_{3}, s_{5}\right) & \left(s_{4}, s_{4}\right) & \left(s_{5}, s_{2}\right) & \left(s_{4}, s_{6}\right) \\
\left(s_{2}, s_{4}\right) & \left(s_{6}, s_{3}\right) & \left(s_{7}, s_{2}\right) & \left(s_{5}, s_{3}\right) & \left(s_{6}, s_{2}\right) & \left(s_{6}, s_{7}\right)
\end{array}\right. \\
& \left.\left(s_{4}, s_{7}\right) \quad\left(s_{6}, s_{1}\right) \quad\left(s_{4}, s_{2}\right) \quad\left(s_{6}, s_{2}\right)\right) \\
& \left(s_{6}, s_{2}\right) \quad\left(s_{7}, s_{5}\right) \quad\left(s_{5}, s_{7}\right) \quad\left(s_{2}, s_{5}\right) ; \\
& \left.\begin{array}{llll}
\left(s_{7}, s_{5}\right) & \left(s_{5}, s_{3}\right) & \left(s_{2}, s_{5}\right) & \left(s_{4}, s_{7}\right)
\end{array}\right) \\
& \widetilde{D}_{3}=\left(\begin{array}{llllll}
\left(s_{3}, s_{4}\right) & \left(s_{4}, s_{6}\right) & \left(s_{5}, s_{3}\right) & \left(s_{6}, s_{4}\right) & \left(s_{5}, s_{1}\right) & \left(s_{7}, s_{4}\right) \\
\left(s_{4}, s_{4}\right) & \left(s_{2}, s_{4}\right) & \left(s_{6}, s_{4}\right) & \left(s_{2}, s_{7}\right) & \left(s_{4}, s_{4}\right) & \left(s_{5}, s_{7}\right) \\
\left(s_{3}, s_{6}\right) & \left(s_{7}, s_{2}\right) & \left(s_{6}, s_{4}\right) & \left(s_{3}, s_{6}\right) & \left(s_{2}, s_{5}\right) & \left(s_{3}, s_{5}\right)
\end{array}\right. \\
& \left.\left(s_{2}, s_{7}\right)\left(s_{3}, s_{5}\right) \quad\left(s_{7}, s_{4}\right) \quad\left(s_{7}, s_{5}\right)\right) \\
& \left(s_{7}, s_{1}\right) \quad\left(s_{3}, s_{2}\right) \quad\left(s_{5}, s_{3}\right) \quad\left(s_{1}, s_{7}\right) ; \text {; } \\
& \begin{array}{lllll}
\left(s_{1}, s_{7}\right) & \left(s_{5}, s_{2}\right) & \left(s_{6}, s_{3}\right) & \left(s_{7}, s_{2}\right)
\end{array}
\end{aligned}
$$


Table 5. Numerical preferences of others-to-worst

\begin{tabular}{|c|c|c|c|c|c|c|c|c|c|c|c|}
\hline \multirow{2}{*}{ Experts } & \multirow{2}{*}{$\begin{array}{c}\text { Worst } \\
\text { criterion }\end{array}$} & \multicolumn{10}{|c|}{ Other criteria } \\
\hline & & $c_{1}$ & $c_{2}$ & $c_{3}$ & $c_{4}$ & $c_{5}$ & $c_{6}$ & $c_{7}$ & $c_{8}$ & $c_{9}$ & $c_{10}$ \\
\hline$e_{1}$ & $c_{4}$ & 0.7906 & 0.8292 & 0.7552 & 0.7071 & 0.7906 & 0.8149 & 0.9014 & 0.8660 & 0.8795 & 1 \\
\hline$e_{2}$ & $c_{1}$ & 0.7071 & 0.8432 & 0.7906 & 0.8292 & 0.8101 & 0.7906 & 1 & 0.9354 & 0.9228 & 0.8795 \\
\hline$e_{3}$ & $c_{3}$ & 0.7552 & 0.8292 & 0.7071 & 0.8149 & 0.8101 & 0.9228 & 0.8795 & 0.9354 & 1 & 0.8705 \\
\hline$e_{4}$ & $c_{5}$ & 0.7906 & 0.8292 & 0.7856 & 0.8101 & 0.7071 & 0.9228 & 0.9642 & 0.8432 & 0.8660 & 1 \\
\hline
\end{tabular}

Table 6. The individual optimal weights of criteria

\begin{tabular}{|c|c|c|c|c|c|c|c|c|c|c|c|}
\hline \multirow{2}{*}{ Experts } & \multicolumn{10}{|c|}{ Criteria weights } & Consistency indicator \\
\cline { 2 - 14 } & $c_{1}$ & $c_{2}$ & $c_{3}$ & $c_{4}$ & $c_{5}$ & $c_{6}$ & $c_{7}$ & $c_{8}$ & $c_{9}$ & $c_{10}$ & \\
\hline$e_{1}$ & 0.0475 & 0.0754 & 0.0328 & 0.0076 & 0.0649 & 0.0744 & 0.1162 & 0.1057 & 0.1184 & 0.3571 & 0.0076 \\
\hline$e_{2}$ & 0.0105 & 0.0720 & 0.0467 & 0.0616 & 0.0720 & 0.0898 & 0.3200 & 0.0980 & 0.1176 & 0.1118 & 0.0105 \\
\hline$e_{3}$ & 0.0660 & 0.0905 & 0.0459 & 0.0660 & 0.1094 & 0.0787 & 0.1172 & 0.1093 & 0.1935 & 0.1235 & 0.0459 \\
\hline$e_{4}$ & 0.0371 & 0.0560 & 0.0624 & 0.0623 & 0.0075 & 0.1223 & 0.1129 & 0.0882 & 0.1045 & 0.3467 & 0.0075 \\
\hline
\end{tabular}

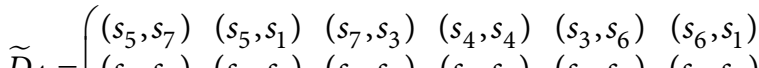

$$
\begin{aligned}
& \widetilde{D}_{4}=\left(\begin{array}{llllll}
\left(s_{6}, s_{3}\right) & \left(s_{4}, s_{1}\right) & \left(s_{2}, s_{6}\right) & \left(s_{6}, s_{3}\right) & \left(s_{7}, s_{2}\right) & \left(s_{3}, s_{6}\right)
\end{array}\right. \\
& \begin{array}{llllll}
\left(s_{5}, s_{2}\right) & \left(s_{6}, s_{1}\right) & \left(s_{2}, s_{3}\right) & \left(s_{6}, s_{3}\right) & \left(s_{7}, s_{4}\right) & \left(s_{2}, s_{6}\right)
\end{array} \\
& \left.\left(s_{5}, s_{2}\right) \quad\left(s_{2}, s_{4}\right) \quad\left(s_{4}, s_{3}\right) \quad\left(s_{2}, s_{7}\right)\right) \\
& \begin{array}{llll}
\left(s_{5}, s_{2}\right) & \left(s_{3}, s_{4}\right) \quad\left(s_{3}, s_{7}\right) \quad\left(s_{5}, s_{1}\right)
\end{array} \text {. } \\
& \begin{array}{llll}
\left(s_{6}, s_{5}\right) & \left(s_{3}, s_{2}\right) & \left(s_{6}, s_{2}\right) & \left(s_{7}, s_{5}\right)
\end{array}
\end{aligned}
$$

According to Eqns (18) and (19), the decision matrices are standardized. Then, we can get the following aggregated decision matrix by Eqn (20):

$$
\begin{aligned}
& \widetilde{D}=\left(\begin{array}{lll}
\left(s_{4.6152}, s_{3.8981}\right) & \left(s_{4.3473}, s_{2.8958}\right) & \left(s_{5.3871}, s_{3.4968}\right)
\end{array}\right. \\
& \widetilde{D}=\left(\begin{array}{llll}
\left(s_{3.9169}, s_{5.1017}\right) & \left(s_{4.7341}, s_{3.0157}\right) & \left(s_{4.6529}, s_{3.5379}\right)
\end{array}\right. \\
& \left(s_{6.4197}, s_{3.1737}\right)\left(s_{5.1683}, s_{2.0237}\right)\left(s_{4.7029}, s_{3.6177}\right) \\
& \left(s_{5.2740}, s_{3.0314}\right)\left(s_{4.3841}, s_{2.0719}\right) \quad\left(s_{6.5371}, s_{2.2974}\right) \\
& \begin{array}{llll}
\left(s_{4.1564}, s_{4.8616}\right) & \left(s_{5.3971}, s_{2.1435}\right) & \left(s_{4.3841}, s_{5.1835}\right)
\end{array} \\
& \begin{array}{llll}
\left(s_{6.5796}, s_{3.9585}\right) & \left(s_{6.4764}, s_{3.0925}\right) & \left(s_{6.6123}, s_{5.0938}\right)
\end{array} \\
& \left(s_{4.5024}, s_{4.7896}\right) \quad\left(s_{4.1793}, s_{2.6922}\right) \quad\left(s_{5.7097}, s_{2.7482}\right) \\
& \begin{array}{llll}
\left(s_{6.0323}, s_{1.2311}\right) & \left(s_{5.4187}, s_{2.9077}\right) & \left(s_{5.2398}, s_{4.5089}\right)
\end{array} \\
& \begin{array}{llll}
\left(s_{6.1446}, s_{4.9076}\right) & \left(s_{6.0452}, s_{2.6703}\right) & \left(s_{6.1914}, s_{2.8252}\right)
\end{array} \\
& \left.\left(s_{4.7835}, s_{5.7177}\right)\right) \\
& \left(s_{5.7487}, s_{2.0451}\right) \text {. } \\
& \left.\left(s_{6.3823}, s_{4.8540}\right)\right)
\end{aligned}
$$

Step 6. Using Eqns (21)-(23), we can compute the measures of the LPF-WASPAS method of these three alternatives. When $\lambda=0.5$, the values of $Q_{i}$ and the corresponding scores are listed in Table 7.

Table 7. The measures of the LPF-WASPAS method with $\lambda=0.5$

\begin{tabular}{|c|c|c|c|}
\hline & $A_{1}$ & $A_{2}$ & $A_{3}$ \\
\hline$Q_{i}^{1}$ & $\left(s_{5.0798}, s_{3.5723}\right)$ & $\left(s_{5.3597}, s_{2.7007}\right)$ & $\left(s_{6.2093}, s_{3.7433}\right)$ \\
\hline$Q_{i}^{2}$ & $\left(s_{4.9042}, s_{4.1960}\right)$ & $\left(s_{5.2293}, s_{3.4427}\right)$ & $\left(s_{6.1336}, s_{4.1313}\right)$ \\
\hline$Q_{i}$ & $\left(s_{4.9937}, s_{3.8716}\right)$ & $\left(s_{5.2955}, s_{3.0492}\right)$ & $\left(s_{6.1719}, s_{3.9325}\right)$ \\
\hline$S\left(Q_{i}\right)$ & 6.0806 & 6.4321 & 6.5813 \\
\hline
\end{tabular}

It can be concluded from Table 7 that the priority of the three alternatives is $A_{3} \succ A_{2} \succ A_{1}$, so alternative $A_{3}$ is the optimal energy-saving building program.

\section{Discussion}

\subsection{Sensitivity analysis}

When the WASPAS method is used to sort alternatives, the selection of $\lambda$ is subjective. According to specific problems, experts may choose the WSM model or WPM model. In this regard, they can adjust the coefficient subjectively. In this subsection, a sensitivity analysis is implemented to verify the stability of the proposed method by changing the value of parameter $\lambda$. When $\lambda$ takes the values from 0 to 1 , the score values of $Q_{i}$ are presented in Table 8 and demonstrated by Figure 1 .

According to Table 8 and Figure 1, we can conclude that the ranking of the three alternatives is always $A_{3} \succ A_{2} \succ A_{1}$. The ranking of alternatives does not change with the value of $\lambda$, which indicates that this method has good stability.

\subsection{Managerial insights of the proposed method}

From the above case study we can conclude that practitioners can use this model to solve MCDM problems in many other fields. In the complex decision-making environment, when uncertainties need to be handled, this method shows advantages. Applicable aspects include green supplier selection, construction site selection, investment project evaluation, performance evaluation, facility location and other issues. In specific applications, practitioners can select appropriate criteria according to their needs, evaluate the performance values of alternatives with respect to the criteria, and get the utility values of the alternatives through the weights of criteria and the performance values of alternatives under each criterion. 


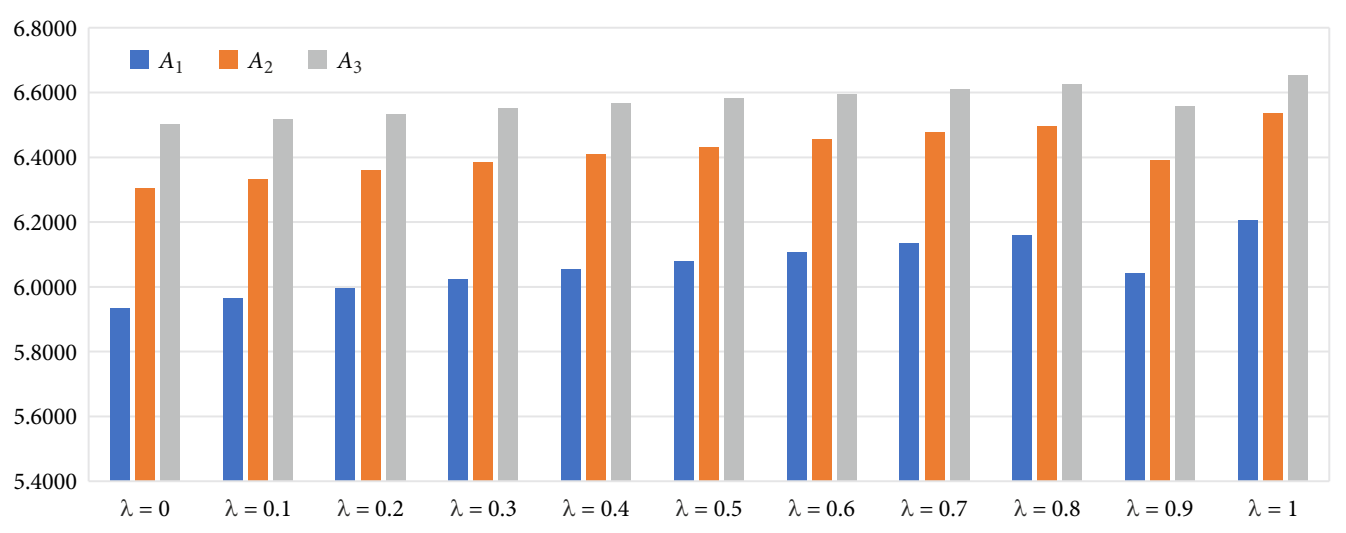

Figure 1 . Sensitivity analysis results for different values of $\lambda$

Table 8. The score values of $Q_{i}$ for different values of $\lambda$

\begin{tabular}{|c|c|c|c|c|c|c|c|c|c|c|c|}
\hline Alternatives & $\lambda=0$ & $\lambda=0.1$ & $\lambda=0.2$ & $\lambda=0.3$ & $\lambda=0.4$ & $\lambda=0.5$ & $\lambda=0.6$ & $\lambda=0.7$ & $\lambda=0.8$ & $\lambda=0.9$ & $\lambda=1$ \\
\hline$A_{1}$ & 5.9348 & 5.9658 & 5.9958 & 6.0249 & 6.0532 & 6.0806 & 6.1073 & 6.1332 & 6.1583 & 6.0422 & 6.2066 \\
\hline$A_{2}$ & 6.3045 & 6.3323 & 6.3589 & 6.3843 & 6.4087 & 6.4321 & 6.4546 & 6.4761 & 6.4968 & 6.3926 & 6.5358 \\
\hline$A_{3}$ & 6.5021 & 6.5185 & 6.5346 & 6.5505 & 6.5661 & 6.5813 & 6.5963 & 6.6111 & 6.6255 & 6.5571 & 6.6537 \\
\hline
\end{tabular}

When the LPF-BWM method is used to determine the weights of criteria, the linguistic terms can better express the preference information of experts for criteria, and establish a consistency model through pairwise comparisons to get the reasonable weights of criteria. The LPFWASPAS method integrates two models at the same time, which can improve the decision-making accuracy when choosing the optimal alternative. In addition, this method involves complex operation process. The development of auxiliary calculation program can be considered to make the decision-making process easier.

\section{Conclusions}

The implementation of energy-saving building is an important measure to improve living comfort, promote environmental protection and reduce pollutant emission. It is also an important part of the sustainable development strategy. Because the energy-saving building program directly affects the actual energy-saving effect, the decision-making at the design stage is of vital importance. Decision-making of energy-saving programs is an MCDM problem, which faces uncertainties in the decision-making process. As for uncertainty modeling, compared with the IFS, the PFS provides more freedom and flexibility for DMs. Furthermore, the LPFS allows experts to use linguistic terms to express membership and non-membership degree, which conforms to decision-making habits of decision-makers and is easier to understand. The BWM and WASPAS method are efficient MCDM methods, which have been widely used for solving practical decision-making problems. When considering the weights of criteria, the BWM needs fewer pairwise comparisons and higher consistency level than that of the AHP, and thus it has great advantages in dealing with decision-making problems that needs to consider a large number of criteria at the same time. The WASPAS method integrates the WSM and WPM models to make the decision results more accurate.

Therefore, this paper extended the BWM and WASPAS method to the LPF environment, and proposed a new multi-expert MCDM method in which the LPF-BWM was developed to derive the weights of criteria, while the LPF-WASPAS was developed to obtain the ranking of all alternatives. To prove the practicability of the proposed method, this paper applied it to the evaluation of energysaving building programs. Then, a sensitivity analysis was implemented through changing the values of parameter in the WASPAS method to verify the stability of the proposed method. The result showed that this method has good applicability and stability.

The limitations of this study and future research directions are as follows:

1) The criteria are determined by experts without considering the needs of consumers. In the further study, it is a good idea to link design needs with customer needs.

2) The psychological and behavioral factors of DMs are not considered in the selection process. In the further research, it is necessary and meaningful to apply prospect theory and regret theory to solve the practical problem of architectural scheme selection.

3) Besides, the research on LPFSs focused more on theoretical and qualitative researches, and the LPFS has not been widely used for practical decisionmaking problems. In future research, more MCDM methods, such as the double normalization-based multiple aggregation method (Liao \& Wu, 2020), can be extended to the LPF environment, so as to compare with our results and apply them to more fields to solve practical problems. 


\section{Funding}

The work was supported by the National Natural Science Foundation of China under Grant 71771156, 71971145.

\section{Author contributions}

Min Huang, Xinli Zhang and Huchang Liao proposed the original idea and conceived the study. Min Huang and Huchang Liao were responsible for developing the method, collecting and analyzing the data. Ruxue Ren and Huchang Liao were responsible for data interpretation. Min Huang and Xinli Zhang wrote the first draft of the article. Ruxue Ren, Huchang Liao, Edmundas Kazimieras Zavadskas and Jurgita Antuchevičienè revised the paper.

\section{Disclosure statement}

The authors have no competing financial, professional, or personal interests from other parties that are related to this paper.

\section{References}

Atanassov, K. T. (1986). Intuitionistic fuzzy sets. Fuzzy Sets and Systems, 20(1), 87-96.

https://doi.org/10.1016/S0165-0114(86)80034-3

Bribian, I. Z., Capilla, A. V., \& Uson, A. A. (2011). Life cycle assessment of building materials: Comparative analysis of energy and environmental impacts and evaluation of the ecoefficiency improvement potential. Building and Environment, 46(5), 1133-1140.

https://doi.org/10.1016/j.buildenv.2010.12.002

Chen, L., \& Pan, W. (2016). BIM-aided variable fuzzy multicriteria decision making of low-carbon building measures selection. Sustainable Cities and Society, 27, 222-232.

https://doi.org/10.1016/j.scs.2016.04.008

Chen, S. M., \& Tan, J. M. (1994). Handling multicriteria fuzzy decision-making problems based on vague set theory. Fuzzy Sets and Systems, 67(2), 163-172.

https://doi.org/10.1016/0165-0114(94)90084-1

Chen, T. Y., \& Tsao, C. Y. (2008). The interval-valued fuzzy TOPSIS method and experimental analysis. Fuzzy Sets and Systems, 159(11), 1410-1428.

https://doi.org/10.1016/j.fss.2007.11.004

Chenari, B., Carrilho, J. D., \& da Silva, M. G. (2016). Towards sustainable, energy-efficient and healthy ventilation strategies in buildings: A review. Renewable \& Sustainable Energy Reviews, 59, 1426-1447. https://doi.org/10.1016/j.rser.2016.01.074

Danish, M. S. S., Senjyu, T., Ibrahimi, A. M., Ahmadi, M., \& Howlader, A. M. (2019). A managed framework for energyefficient building. Journal of Building Engineering, 21, 120128. https://doi.org/10.1016/j.jobe.2018.10.013

Delgarm, N., Sajadi, B., Kowsary, F., \& Delgarm, S. (2016). Multiobjective optimization of the building energy performance: A simulation-based approach by means of Particle Swarm Optimization (PSO). Applied Energy, 170, 293-303. https://doi.org/10.1016/j.apenergy.2016.02.141

Deveci, M., Canitez, F., \& Gokasar, I. (2018). WASPAS and TOPSIS based interval type-2 fuzzy MCDM method for a selection of a car sharing station. Sustainable Cities and Society, 41, 777-791. https://doi.org/10.1016/j.scs.2018.05.034
Garg, H. (2018). Linguistic Pythagorean fuzzy sets and its applications in multiattribute decision-making process. International Journal of Intelligent Systems, 33(6), 1234-1263.

https://doi.org/10.1002/int.21979

Geng, G., Wang, Z. X., Zhao, J., \& Zhu, N. (2015). Suitability assessment of building energy saving technologies for office buildings in cold areas of China based on an assessment framework. Energy Conversion and Management, 103, 650664. https://doi.org/10.1016/j.enconman.2015.06.087

Guo, S., \& Zhao, H. R. (2017). Fuzzy best-worst multi-criteria decision-making method and its applications. KnowledgeBased Systems, 121, 23-31. https://doi.org/10.1016/j.knosys.2017.01.010

Harish, V., \& Kumar, A. (2016). A review on modeling and simulation of building energy systems. Renewable \& Sustainable Energy Reviews, 56, 1272-1292. https://doi.org/10.1016/j.rser.2015.12.040

Heravi, G., Fathi, M., \& Faeghi, S. (2017). Multi-criteria group decision-making method for optimal selection of sustainable industrial building options focused on petrochemical projects. Journal of Cleaner Production, 142, 2999-3013. https://doi.org/10.1016/j.jclepro.2016.10.168

Huang, M. Q., \& Wang, B. (2014). Evaluating green performance of building products based on gray relational analysis and analytic hierarchy process. Environment Progress \& Sustainable Energy, 33(4), 1389-1395. https://doi.org/10.1002/ep.11884

Keshavarz Ghorabaee, M., Zavadskas, E. K., Amiri, M., \& Esmaeili, A. (2016). Multi-criteria evaluation of green suppliers using an extended WASPAS method with interval type2 fuzzy sets. Journal of Cleaner Production, 137, 213-229. https://doi.org/10.1016/j.jclepro.2016.07.031

Khoshnava, S. M., Rostami, R., Valipour, A., Ismail, M., \& Rahmat, A. R. (2018). Rank of green building material criteria based on the three pillars of sustainability using the hybrid multi criteria decision making method. Journal of Cleaner Production, 173, 82-99. https://doi.org/10.1016/j.jclepro.2016.10.066

Kim, J. J. (2017). Economic analysis on energy saving technologies for complex manufacturing building. Resources Conservation and Recycling, 123, 249-254.

https://doi.org/10.1016/j.resconrec.2016.03.018

Lee, B., Trcka, M., \& Hensen, J. L. M. (2011). Embodied energy of building materials and green building rating systems - A case study for industrial halls. Sustainable Cities and Society, 1(2), 67-71. https://doi.org/10.1016/j.scs.2011.02.002

Li, J., Wang, J. Q., \& Hu, J. H. (2019). Multi-criteria decisionmaking method based on dominance degree and BWM with probabilistic hesitant fuzzy information. International Journal of Machine Learning and Cybernetics, 10(7), 1671-1685. https://doi.org/10.1007/s13042-018-0845-2

Liao, H. C., Qin, R., Gao, C. Y., Wu, X.L., Hafezalkotob, A., \& Herrera, F. (2019). Score-HeDLiSF: A score function of hesitant fuzzy linguistic term set based on hesitant degrees and linguistic scale functions: an application to unbalanced hesitant fuzzy linguistic MULTIMOORA. Information Fusion, 48, 39-54. https://doi.org/10.1016/j.inffus.2018.08.006

Liao, H. C., \& Wu, X. L. (2020). DNMA: A double normalization-based multiple aggregation method for multi-expert multi-criteria decision making. Omega, 94, 102058. https://doi.org/10.1016/j.omega.2019.04.001

Liu, H. C., Quan, M. Y., Li, Z. W., \& Wang, Z. L. (2019). A new integrated MCDM model for sustainable supplier selection under interval-valued intuitionistic uncertain linguistic environment. Information Sciences, 486, 254-270. https://doi.org/10.1016/j.ins.2019.02.056 
Liu, Y., Yang, L., Zheng, W. X., Liu, T., Zhang, X. R., \& Liu, J. P. (2018). A novel building energy efficiency evaluation index: Establishment of calculation model and application. Energy Conversion and Management, 166, 522-533. https://doi.org/10.1016/j.enconman.2018.03.090

Lu, S. L., Fan M. C., \& Zhao, Y. Q. (2018). A system to preevaluate the suitability of energy-saving technology for green buildings. Sustainability, 10(10), 3777. https://doi.org/10.3390/su10103777

Mathiyazhagan, K., Gnanavelbabu, A., \& Lokesh Prabhuraj, B. (2019). A sustainable assessment model for material selection in construction industries perspective using hybrid MCDM approaches. Journal of Advances in Management Research, 16(2), 234-259. https://doi.org/10.1108/JAMR-09-2018-0085

Mi, X. M., \& Liao, H. C. (2019). An integrated approach to multiple criteria decision making based on the average solution and normalized weights of criteria deduced by the hesitant fuzzy best worst method. Computers \& Industrial Engineering, 133, 83-94. https://doi.org/10.1016/j.cie.2019.05.004

Mi, X. M., Tang, M., Liao, H. C., Shen, W. J., \& Lev, B. (2019). The state-of-the-art survey on integrations and applications of the best worst method in decision making: Why, what, what for and what's next? Omega, 87, 205-225. https://doi.org/10.1016/j.omega.2019.01.009

Mishra, A. R., \& Rani, P. (2018). Interval-valued intuitionistic fuzzy WASPAS method: application in reservoir flood control management policy. Group Decision and Negotiation, 27(6), 1047-1078. https://doi.org/10.1007/s10726-018-9593-7

Mou, Q., Xu, Z. S., \& Liao, H. C. (2016). An intuitionistic fuzzy multiplicative best-worst method for multi-criteria group decision making. Information Sciences, 374, 224-239. https://doi.org/10.1016/j.ins.2016.08.074

Mou, Q., Xu, Z. S., \& Liao, H. C. (2017). A graph based group decision making approach with intuitionistic fuzzy preference relations. Computer and Industrial Engineering, 110, 138-150. https://doi.org/10.1016/j.cie.2017.05.033

Ren, R. X., Liao, H. C., Al-Barakati, A., \& Cavallaro, F. (2019). Electric vehicle charging station site selection by an integrated SWARA-WASPAS method with hesitant fuzzy linguistic information. Transformations in Business \& Economics, 18(2), 103-123.

Rezaei, J. (2015). Best-worst multi-criteria decision-making method. Omega, 53, 49-57.

https://doi.org/10.1016/j.omega.2014.11.009

Rezaei, J. (2016). Best-worst multi-criteria decision-making method: some properties and a linear model. Omega, 64, 126-130. https://doi.org/10.1016/j.omega.2015.12.001

Sanayei, A., Mousavi, S. F., \& Yazdankhah, A. (2010). Group decision making process for supplier selection with VIKOR under fuzzy environment. Expert Systems with Applications, 37(1), 24-30. https://doi.org/10.1016/j.eswa.2009.04.063

Si, J., \& Marjanovic-Halburd, L. (2018). Criteria weighting for green technology selection as part of retrofit decision-making process for existing non-domestic buildings. Sustainable Cities and Society, 41, 625-638. https://doi.org/10.1016/j.scs.2018.05.051

Si, J., Marjanovic-Halburd, L., Nasiri, F., \& Bell, S. (2016). Assessment of building-integrated green technologies: A review and case study on applications of Multi-Criteria Decision Making (MCDM) method. Sustainable Cities and Society, 27, 106-115. https://doi.org/10.1016/j.scs.2016.06.013
Turskis, Z., Zavadskas, E. K., Antucheviciene, J., \& Kosareva, N. (2015). A hybrid model based on fuzzy AHP and fuzzy WASPAS for construction site selection. International Journal of Computers Communication \& Control, 10(6), 873-888. https://doi.org/10.15837/ijccc.2015.6.2078

Vaidya, O. S., \& Kumar, S. (2006). Analytic hierarchy process: An overview of applications. European Journal of Operational Research, 169(1), 1-29. https://doi.org/10.1016/j.ejor.2004.04.028

Wang, J. Q., Wu, J. T., Wang, J., Zhang, H. Y., \& Chen, X. H. (2014). Interval-valued hesitant fuzzy linguistic sets and their applications in multi-criteria decision-making problems. Information Sciences, 288, 55-72. https://doi.org/10.1016/j.ins.2014.07.034

Wang, X., Feng, W., Cai, W. G., Ren, H., Ding, C., \& Zhou, N. (2019). Do residential building energy efficiency standards reduce energy consumption in China? - A data-driven method to validate the actual performance of building energy efficiency standards. Energy Policy, 131, 82-89. https://doi.org/10.1016/j.enpol.2019.04.022

Yager, R. R. (2014). Pythagorean membership grades in multicriteria decision making. IEEE Transaction on Fuzzy Systems, 22(4), 958-965. https://doi.org/10.1109/TFUZZ.2013.2278989

Yu, X. H., Zhang, S. J., Liao, X. L., \& Qi, X. L. (2018). ELECTRE methods in prioritized MCDM environment. Information Sciences, 424, 301-316. https://doi.org/10.1016/j.ins.2017.09.061

Zavadskas, E. K., Turskis, Z., Antucheviciene, J., \& Zakarevicius, A. (2012). Optimization of weighted aggregated sum product assessment. Elektronika ir Elektrotechnika, 122(6), 3-6. https://doi.org/10.5755/j01.eee.122.6.1810 